\title{
A Spectrophotometric Analysis of Color Changes in Metal Ceramic Restorations by Varying Porcelain Thickness and Repeated Firings: An in vitro Study
}

\author{
${ }^{1}$ Ramesh Raju, ${ }^{2}$ Sunantha Selvaraj, ${ }^{3}$ Vidhya Zankari, ${ }^{4}$ Manonmani Vijayakumar
}

\begin{abstract}
The dental profession has long been concerned with the problem of matching the appearance of porcelain restorations with a patient's natural dentition. The esthetics of any restoration depends on outline form, surface form, translucency and color.

Purpose: The objective of this study is to find out the adequate porcelain thickness required for metal ceramic restorations to match the color of the shade guide and effect of repeated firing on quality and physical characteristics of dental ceramics.
\end{abstract}

Methods: Preparation of samples done first by preparing alloy substructure. A total of 15 samples of uniform thickness $0.5 \mathrm{~mm}$ was prepared using $\mathrm{Ni}-\mathrm{Cr}$ alloy. Fusion of porcelain to alloy substructure done. Fifteen samples, five $0.5 \mathrm{~mm}$ thickness samples, five $1 \mathrm{~mm}$ samples and five $1.5 \mathrm{~mm}$ porcelain thickness samples were prepared. Color evaluation done by spectrophotometer.

Statistic analysis: Statistic analysis methods employed in the present study were ANOVA-one way, Scheffe's post hoc test and paired samples ' $t$ ' test.

Conclusion: The thickness of porcelain significantly affects the color of a given porcelain sample. Increasing the thickness gives better results. On repeated firings two and 10 firing did not affect the color stability.

Keywords: Color anaylsis, Ni-Cr alloy, Porcelain thickness, Spectrophotometer.

How to cite this article: Raju R, Selvaraj S, Zankari V, Vijayakumar M. A Spectrophotometric Analysis of Color Changes in Metal Ceramic Restorations by Varying Porcelain Thickness and Repeated Firings: An in vitro Study. Int J Prosthodont Restor Dent 2015;5(2):38-43

Source of support: Nil

Conflict of interest: None

\footnotetext{
${ }^{1,3,4}$ Reader, ${ }^{2}$ Senior Lecturer

1,2Department of Prosthodontics, Vinayaka Mission's Sankarachariyar Dental College, Salem, Tamil Nadu, India

${ }^{3}$ Department of Prosthodontics, KSR Institute of Dental Sciences, Tiruchengode, Tamil Nadu, India

${ }^{4}$ Department of Prosthodontics, Vivekananda Dental College and Hospital, Elaiyampalayam, Tamil Nadu, India
}

Corresponding Author: Sunantha Selvaraj, Senior Lecturer Department of Prosthodontics, Vinayaka Mission's Sankarachariyar Dental College, Salem, Tamil Nadu, India Phone: 7708225522, e-mail: drsunujai@yahoo.co.in

\section{INTRODUCTION}

Metal ceramic crowns are the most commonly prescribed fixed prostheses for the full-coverage restoration. However, the opaque substructure of the metal ceramic crowns restricts its potential in areas of high esthetic importance. Color reproducibility is the ability of dental porcelain to match the color of its respective shade guide without the help of any extrinsic colorants. ${ }^{1,2}$ Several factors affect the ability of a porcelain system to produce an acceptable match with corresponding shade guides. Porcelain type, ${ }^{3}$ underlying metal, ${ }^{4,5}$ batch $^{6}$ manufacturer, opaque thickness, surface texture, ${ }^{7}$ layering of porcelain, ${ }^{8}$ ceramic thickness ${ }^{9}$ external lighting source, and observers visual perception, all contribute to perceptible differences between the resultant shade of dental porcelain and their respective shade tabs.

Acceptability of shade match is a qualitative assessment made by visual comparison of a specimen (ceramic restoration) to a target (shade tab or natural dentition). Color assessment is a complex psychophysiologic process, which is subject to numerous variables. Inconsistencies in a person's ability to reliably select color matches are

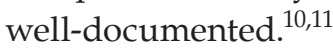

Current photometric and colorimetric instruments are capable of reliably quantifying color of both extracted teeth and dental porcelain. These instruments measure color and express it in terms of three coordinate values $\left(\mathrm{L}^{*}, \mathrm{a}^{*}, \mathrm{~b}^{*}\right)$, which locate the object's color within the CIELAB color space. ${ }^{12-14}$

The objective of this study is to spectrophotometrically evaluate the dental porcelain color by,

- Varying the dental porcelain thickness

- Repeated firing of dental porcelain.

\section{MATERIALS}

Base Metal Alloy namely Nickel-Chrome Alloy (4-all Ivoclar Vivadent; Batch-G10288) was used for metal coping. Dental ceramic materials (Vita VMK—95; B2 shade: Vita Zahnfabrik H Rauter GMBH and co, KG, Germany) were used. Armamentarium used for the study were induction casting machine-(Bego, Italy), unident burnout furnace, vita ceramic furnace (Madimat 
90, Manfredi, Italy) and spectrophotometer (CR-321, Minolta, Japan).

\section{METHODS}

The tested samples had a flat cylindrical metal base, over which was baked on accompanying porcelain superstructure. A nickel chromium non-precious alloy was used to bond with vita VMK—95 porcelain with B2 shade.

- Preparation of alloy substructure: For standardizing the thickness of the metal substructure, patterns for the substructure were fabricated from $0.5 \mathrm{~mm}$ thick acetyl plastic sheets. The sheet was cut into round pieces of $1.5 \mathrm{~cm}$ in diameter. It is uniformly cut using a customized brass jig. A total of 15 samples of uniform thickness $0.5 \mathrm{~mm}$ was prepared using Ni-Cr alloy (Fig. 1).

- Condensation of ceramic over metal substructure: Fabrications of mold for uniform ceramic build-up: An aluminium mold was used to standardize the shape of the porcelain build-up. It is used for construction of uniform thickness of specimens. It has a plunger and a cylinder. The plunger in made in three different lengthwise when inserted into the standard size cylinder the plunger will be short by 1, 1.5 and $2 \mathrm{~mm}$ so as to give space for the porcelain material (Fig. 2). $1 \mathrm{~mm}$ means $0.5 \mathrm{~mm}$ for metal and $0.5 \mathrm{~mm}$ for the dentin porcelain. $1.5 \mathrm{~mm}$ means $0.5 \mathrm{~mm}$ for metal and $1 \mathrm{~mm}$ for dentin porcelain and $2 \mathrm{~mm}$ means $0.5 \mathrm{~mm}$ for substructure and $1.5 \mathrm{~mm}$ for dentin porcelain. Ceramic application: Ceramic powders were mixed with modeling liquid and placed on the metal substructure, and then the metal substructure along with the dentin porcelain is placed in the cylinder. The plunger is placed into the cylinder and condensed. Three different lengths of plungers were used to prepare samples of three different thicknesses. Fifteen samples, $0.5 \mathrm{~mm}$ thickness samples, $1 \mathrm{~mm}$ samples and $1.5 \mathrm{~mm}$ porcelain thickness, five samples in each were prepared (Fig. 3).

Finishing of ceramic over structure: The vertical sides of the specimens were trimmed flush with the metal by means of an abrasive diamond instrument. Specimen thickness was refined with wet 180 grit silicon carbide paper on a glass slab. The thickness of each ground specimen was then measured nine times along its length with a micrometer and corrected as necessary until the desired thickness of dentin was achieved (0.5, 1 and $1.5 \mathrm{~mm})$.

The porcelain was ultrasonically cleaned in distilled water for 5 minutes, and then glazed by holding the porcelain at manufacturer's recommended temperature for 2 minutes in air. The specimens were then removed and allowed to cool under a glass beaker.

- Color evaluation by spectrophotometer: The samples were individually analyzed in a spectrophotometer. It measured reflectance of the sample and a standard (white opal) every $10 \mathrm{~nm}$ over the visible spectrum (400-700 nm) so that absolute reflectance of the sample is recorded. International Commission an Illumination standard illuminant D65 was used for all measurement. Calibration was accomplished at the beginning of each measurement. All data points were recorded using standard CIE color parameters. The color system followed in this study is CIELAB. ${ }^{14,15}$

The magnitude and direction or shift of the difference between two color stimuli can be identified. ${ }^{16} \mathrm{~L}$ is the lightness coordinate (y-axis) and, $a^{*}$ is the redness-greenness coordinate (x-axis) and $b^{*}$ is the yellowness-blueness coordinate (z-axis). The colors of each opponent pair are indicated by the positive and negative values of $a^{*}$ and $b^{*}$. The $L^{*}, a^{*}$ and $b^{*}$ values are derived from the Tristimulus values $X, Y$ and $Z$ (Fig. 4).

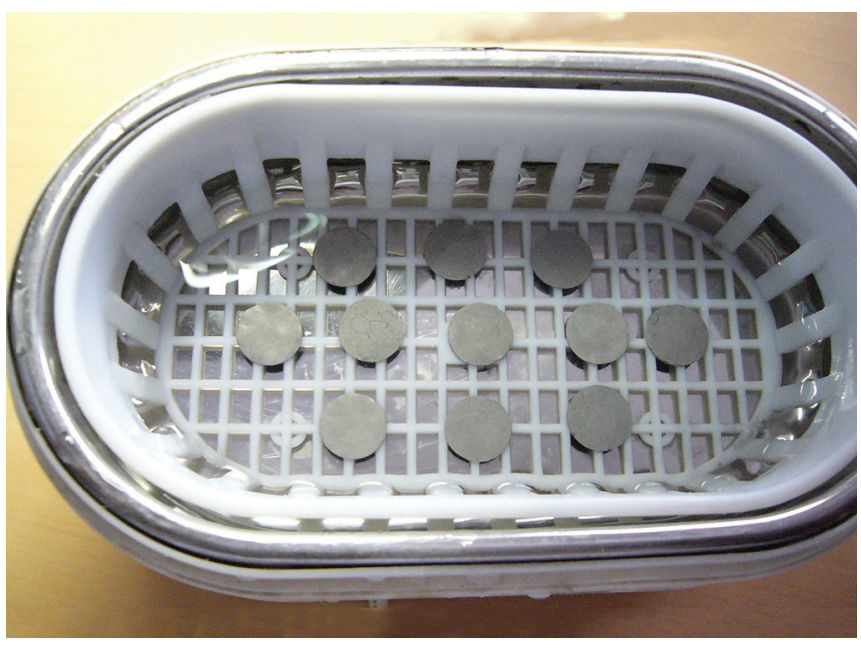

Fig. 1: Fifteen Ni-Cr alloy samples of uniform thickness $0.5 \mathrm{~mm}$

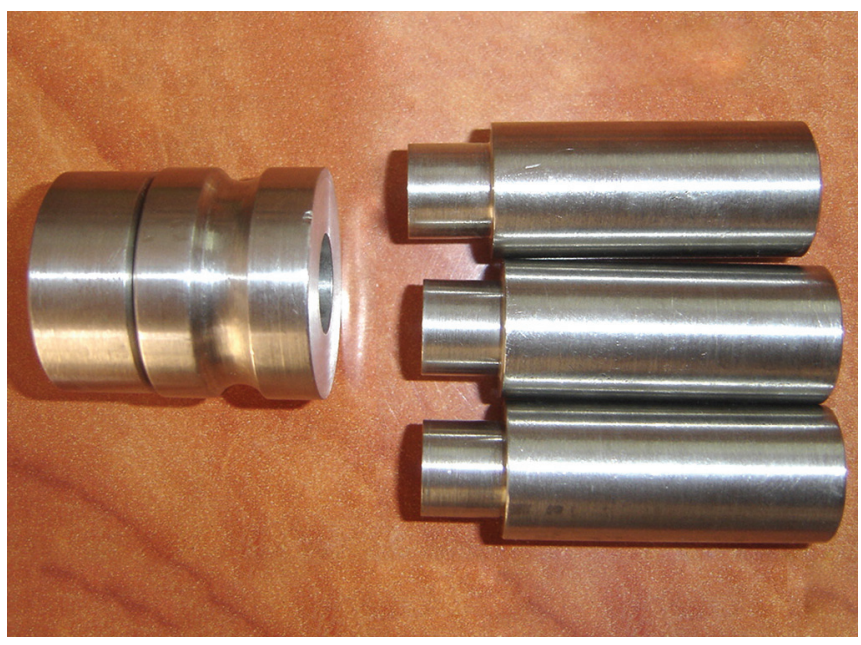

Fig. 2: Metal plunger of thickness 1, 1.5 and $2 \mathrm{~mm}$ 
- Color differences in CIELAB system: In the CIELAB system, the total color difference $(\Delta \mathrm{E})$ is evaluated from combination of three independent color variables, namely: $\Delta \mathrm{L}, \Delta \mathrm{a}, \Delta \mathrm{b}$.

The lightness difference in the $L^{*}$ axis expressed by $\Delta L$. The sign of the difference indicates the direction of the variation in relation to psychosensorial perception:

A negative $L^{*}$ value means a shift to darker (black).

A positive $L^{*}$ value means a shift to lighter (white).

The red-green color difference in the $\mathrm{a}^{*}$ axis, expressed by $\Delta$,

Positive $\mathrm{a}^{*}$ means more red.

Negative $a^{*}$ means more green,

The yellow-blue color difference on the $b^{*}$ axis, expressed by $\Delta \mathrm{b}$.

Positive $b^{*}$ means more yellow.

Negative $b^{*}$ means more blue,

These values $(\Delta \mathrm{a}$ and $\Delta \mathrm{b})$ can also be accompanied by a more comprehensive parameter-the chromaticity difference, $\Delta c$, summarizing their contribution in the color difference. In the total color difference $(\Delta \mathrm{E})$, the chromaticity difference $(\Delta c)$ respondents the variation

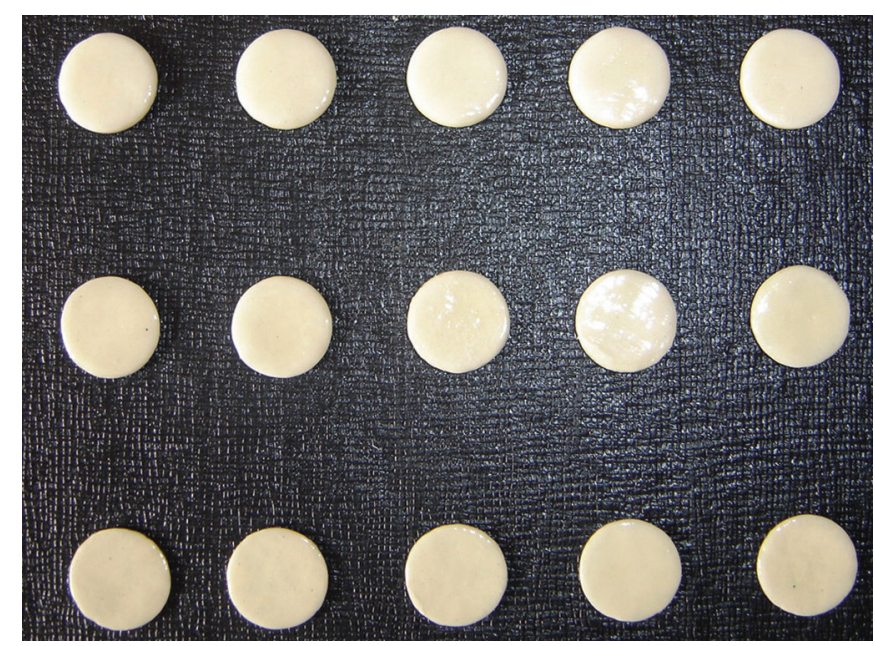

Fig. 3: $0.5,1$ and $1.5 \mathrm{~mm}$ porcelain thickness, 5 samples each

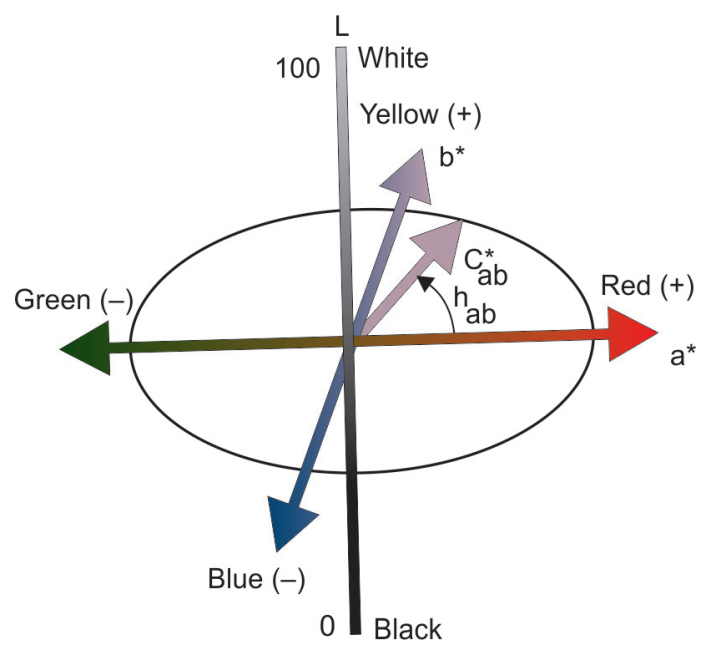

Fig. 4: Tristimulus values $X, Y$ and $Z$ axes which is not due to lightness $(\Delta \mathrm{L})$.

$$
\begin{aligned}
& \Delta \mathrm{E}=[(\Delta \mathrm{L}) 2+(\Delta \mathrm{a}) 2+(\Delta \mathrm{b}) 2] 1 / 2 \\
& \Delta \mathrm{E}=[(\Delta \mathrm{L}) 2+(\Delta \mathrm{c}) 2] 1 / 2 \\
& \Delta \mathrm{c}=[(\Delta \mathrm{a}) 2+(\Delta \mathrm{b}) 2] 1 / 2
\end{aligned}
$$

The $L^{*}, a^{*}$ and $b^{*}$ method of expressing color differences is very practical and if frequently used. Red, Green and Yellow and blue can be used to estimate the direction of color correction when one is required. Finally, the color difference of the sample with the standard shade guide was calculated by using the same 1976 CIE L a b (CIELAB) color difference equation.

$$
\Delta \mathrm{E}=[(\Delta \mathrm{L}) 2+(\Delta \mathrm{a}) 2+(\Delta \mathrm{b}) 2] 1 / 2
$$

\section{STATISTIC ANALYSIS}

Statistic analysis methods employed in the present study were:

- Analysis of variance (ANOVA) —one way

- Scheffe's post hoc test

- Paired samples ' $t$ ' test.

\section{RESULTS}

One-way ANOVA revealed a significant difference between mean lightness values $(F=58.510 ; p<0.000)$, mean $a^{*}$ values $(F=7.139 ; p<0.000)$, mean $b^{*}$ values $(\mathrm{F}=38.845 ; \mathrm{p}<0.000)$ and mean $\mathrm{c}^{*}$ values $(\mathrm{F}=52.504$; $\mathrm{p}<0.000$ ) of different porcelain thickness in two firings of $0.5,1.0,1.5 \mathrm{~mm}$ and standard. Further Scheffe's post hoc test revealed that as the thickness increased lightness also increased linearly, having standard highest, a* value decreases and get closer to the standard, $\mathrm{b}^{*}$ value decreases and get closer to the standard and chroma $\mathrm{c}^{*}$ value decreases and match the standard.

One-way ANOVA revealed a significant difference between mean lightness values ( $\mathrm{F}=50.162 ; \mathrm{p}<0.000)$, mean $\mathrm{a}^{*}$ values $(\mathrm{F}=50.162 ; \mathrm{p}<0.000)$, mean $\mathrm{b}^{*}$ values $(\mathrm{F}=$ 27.146; $\mathrm{p}<0.000)$ and mean $\mathrm{c}^{*}$ values $(\mathrm{F}=27.146 ; \mathrm{p}<0.000)$ of different porcelain thickness in two firings of $0.5,1.0$, $1.5 \mathrm{~mm}$ and standard. Further Scheffe's post hoc test revealed that as the thickness increased lightness also increased linearly, close to the standard, $\mathrm{a}^{*}$ value decreases and get closer to the standard, so there is decrease in red green axis. The $b^{*}$ value was found to be least in $1.5 \mathrm{~mm}$ and highest in $0.5 \mathrm{~mm}$. As thickness increases there is decrease in yellow blue axis and chroma $\mathrm{c}^{*}$ value was found to be least in $1.5 \mathrm{~mm}$ and highest in $0.5 \mathrm{~mm}$. There is decrease in chroma as the thickness increases.

Descriptive and paired samples statistics for various color parameters for Porcelain thickness at parameters $0.5 \mathrm{~mm}$ (Table 1 and Graph 1), $1 \mathrm{~mm}$ (Table 2 and Graph 2) and $1.5 \mathrm{~mm}$ (Table 3 and Graph 3). Shows no significant 
difference between mean values of two and 10 firings as, all the obtained ' $t$ ' values found to be non-significant.

Color difference $(\Delta \mathrm{E})$ on varying ceramic thickness on comparison with standard shade guide:

- $\Delta \mathrm{L}-\mathrm{L}_{2}-\mathrm{L}_{1}$

- $\Delta \mathrm{a}-\mathrm{a}_{2}-\mathrm{a}_{1}$

- $\Delta \mathrm{b}-\mathrm{b}_{2}-\mathrm{b}_{1}$

- $\Delta \mathrm{E}^{*}=\sqrt{(\Delta \mathrm{L})^{2}+(\Delta a)^{2}+(\Delta b)^{2}}$

All the 15 samples were compared to the control (shade guide) to find out the delta E (Table 4). The mean of $1.5 \mathrm{~mm}$ is very closely matching the shade guide. So, adequate reduction of tooth or adequate thickness of porcelain is necessary to match the desired color. Color difference $(\Delta \mathrm{E})$ on repeated firings (i.e. two firings and ten firings) (Table 5). The results indicate no change in color due to repeated firings.

Table 1: Descriptive and paired samples statistics for various color parameters for porcelain thickness at $0.5 \mathrm{~mm}$

\begin{tabular}{lllll}
\hline Parameter & Mean & $\begin{array}{l}\text { Std. } \\
\text { Deviation }\end{array}$ & 't'-value & Significance \\
\hline $\mathrm{L}_{1}$ & 73.7140 & 0.4033 & 1.529 & $0.201(\mathrm{NS})$ \\
$\mathrm{L}_{2}$ & 73.5140 & 0.5235 & & \\
$\mathrm{a}_{1}$ & 2.4700 & 0.4385 & 2.772 & $0.050(\mathrm{~S})$ \\
$\mathrm{a}_{2}$ & 2.3040 & 0.3789 & & \\
$\mathrm{~b}_{1}$ & 21.4000 & 1.2360 & 1.833 & $0.141(\mathrm{NS})$ \\
$\mathrm{b}_{2}$ & 21.0160 & 1.6439 & & \\
$\mathrm{c}_{1}$ & 21.5000 & 1.2228 & \multirow{2}{*}{1.614} & $0.182(\mathrm{NS})$ \\
$\mathrm{C}_{2}$ & 21.1400 & 1.6451 & &
\end{tabular}

NS: Not significant; S: Significant

Table 2: Descriptive and paired samples statistics for various color parameters for porcelain thickness at $1 \mathrm{~mm}$

\begin{tabular}{lllll}
\hline Parameter & Mean & $\begin{array}{l}\text { Std. } \\
\text { Deviation }\end{array}$ & 't'-value & Significance \\
\hline $\mathrm{L}_{1}$ & 74.7480 & 0.4937 & 1.938 & $0.125(\mathrm{NS})$ \\
$\mathrm{L}_{2}$ & 74.4580 & 0.5471 & & \\
$\mathrm{a}_{1}$ & 2.0860 & 0.2657 & 2.291 & $0.084(\mathrm{NS})$ \\
$\mathrm{a}_{2}$ & 1.7640 & 0.2992 & & \\
$\mathrm{~b}_{1}$ & 18.9520 & 0.8268 & 2.711 & $0.053(\mathrm{NS})$ \\
$\mathrm{b}_{2}$ & 18.7600 & 0.7558 & & \\
$\mathrm{c}_{1}$ & 19.4580 & 0.3300 & 1.663 & $0.172(\mathrm{NS})$ \\
$\mathrm{c}_{2}$ & 18.8420 & 0.7309 & & \\
\hline
\end{tabular}

NS: Not significant

Table 3: Descriptive and paired samples statistics for various color parameters for porcelain thickness at $1.5 \mathrm{~mm}$

\begin{tabular}{lllll}
\hline Parameter & Mean & $\begin{array}{l}\text { Std. } \\
\text { Deviation }\end{array}$ & 't'-value & Significance \\
\hline $\mathrm{L}_{1}$ & 76.0160 & 0.7348 & 2.307 & $0.082(\mathrm{NS})$ \\
$\mathrm{L}_{2}$ & 75.7060 & 0.8072 & & \\
$\mathrm{a}_{1}$ & 1.7480 & 0.1693 & 1.884 & $0.133(\mathrm{~S})$ \\
$\mathrm{a}_{2}$ & 1.5360 & 0.2989 & & \\
$\mathrm{~b}_{1}$ & 15.9880 & 0.6621 & 2.170 & $0.096(\mathrm{NS})$ \\
$\mathrm{b}_{2}$ & 15.7640 & 0.4845 & & \\
$\mathrm{c}_{1}$ & 16.0820 & 0.6494 & 2.437 & $0.071(\mathrm{NS})$ \\
\hline
\end{tabular}

NS: Not significant; S: Significant

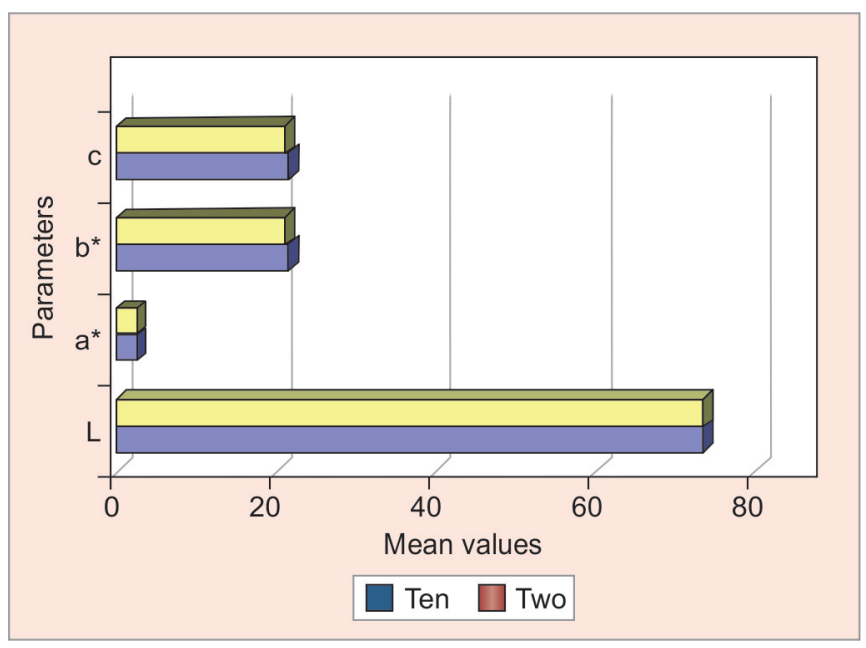

Graph 1: Comparison of various parameters for two and 10 firings at $0.5 \mathrm{~mm}$

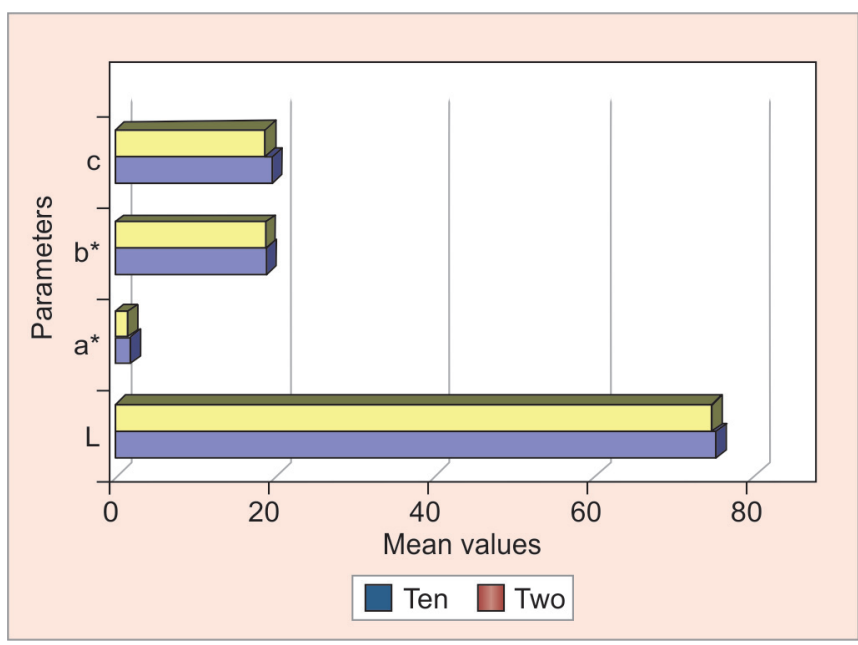

Graph 2: Comparison of various parameters for two and 10 firings at $1.0 \mathrm{~mm}$

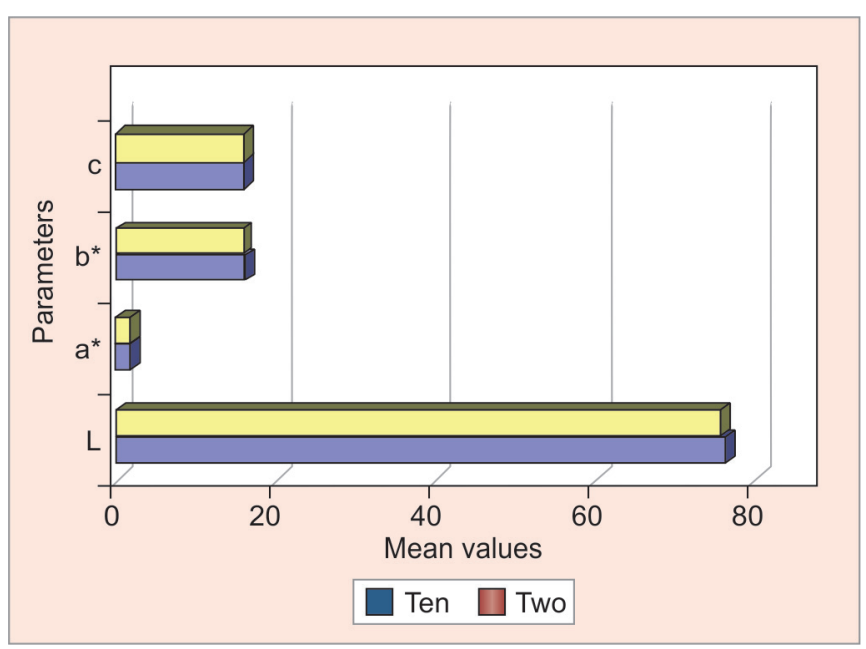

Graph 3: Comparison of various parameters for two and 10 firings at $1.5 \mathrm{~mm}$

\section{DISCUSSION}

In the first part of the study opaque and dentin porcelain were fired on the nickel chromium metal substructure 
Table 4: Color difference $(\Delta \mathrm{E})$ on varying ceramic thickness on comparison with standard shade guide

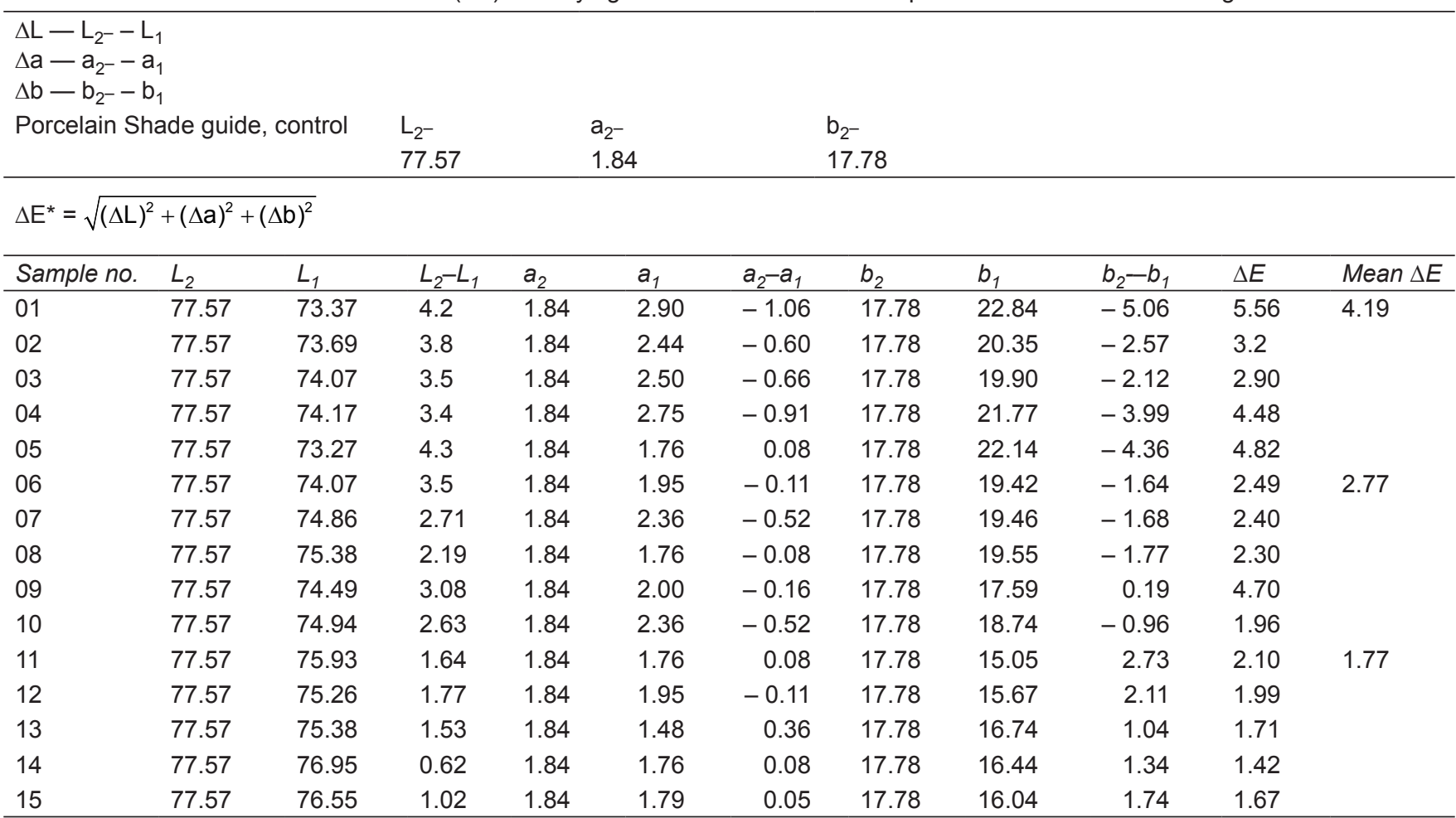

Table 5: Color difference $(\Delta \mathrm{E})$ on repeated firings (Two firings and 10 firings)

\begin{tabular}{|c|c|c|c|c|c|c|c|c|c|c|c|}
\hline \multirow{2}{*}{\multicolumn{12}{|c|}{$\begin{array}{l}L_{1}, a_{1}, b_{1}-\text { Two firings } \\
L_{2}, a_{2}, b_{2}-10 \text { firings } \\
\Delta L-L_{2}-L_{1} \\
\Delta a-a_{2}-a_{1} \\
\Delta b-b_{2}-b_{1} \\
\Delta E^{*}=\sqrt{(\Delta L)^{2}+(\Delta a)^{2}+(\Delta b)^{2}}\end{array}$}} \\
\hline & & & & & & & & & & & \\
\hline Sample no. & $L_{2}$ & $L_{1}$ & $L_{2}-L_{1}$ & $a_{2}$ & $a_{1}$ & $a_{2}-a_{1}$ & $b_{2}$ & $b_{1}$ & $b_{2}-b_{1}$ & $\Delta E$ & Mean $\Delta E$ \\
\hline 01 & 73.25 & 73.37 & -0.12 & 2.80 & 2.90 & -0.10 & 22.80 & 22.84 & -0.04 & 0.16 & \\
\hline 02 & 72.97 & 73.69 & -0.72 & 2.33 & 2.44 & -0.10 & 20.01 & 20.35 & -0.34 & 0.80 & \\
\hline 03 & 74.04 & 74.07 & -0.03 & 2.22 & 2.50 & -0.28 & 18.70 & 19.90 & -1.20 & 1.23 & 0.55 \\
\hline 04 & 74.11 & 74.17 & -0.06 & 2.42 & 2.75 & -0.35 & 21.60 & 21.77 & -0.17 & 0.39 & \\
\hline 05 & 73.20 & 73.27 & -0.07 & 1.75 & 1.76 & -0.01 & 21.97 & 22.14 & -0.17 & 0.18 & \\
\hline 06 & 74.06 & 74.07 & -0.01 & 1.36 & 1.95 & -0.59 & 19.37 & 19.42 & -0.05 & 0.59 & \\
\hline 07 & 74.71 & 74.86 & -0.15 & 1.65 & 2.36 & -0.71 & 19.21 & 19.46 & -0.25 & 0.76 & \\
\hline 08 & 75.31 & 75.38 & -0.07 & 1.70 & 1.76 & -0.06 & 19.11 & 19.55 & -0.44 & 0.44 & 0.61 \\
\hline 09 & 74.10 & 74.49 & -0.39 & 1.99 & 2.00 & -0.01 & 17.51 & 17.59 & -0.08 & 0.39 & \\
\hline 10 & 74.11 & 74.94 & -0.83 & 2.12 & 2.36 & -0.24 & 18.60 & 18.74 & -0.14 & 0.87 & \\
\hline 11 & 75.10 & 75.93 & -0.83 & 75.10 & 1.76 & -0.65 & 15.0 & 15.05 & -0.05 & 1.05 & \\
\hline 12 & 75.00 & 75.26 & -0.26 & 75.00 & 1.95 & -0.05 & 15.60 & 15.67 & -0.07 & 0.27 & \\
\hline 13 & 75.31 & 75.38 & -0.07 & 75.31 & 1.48 & -0.07 & 16.13 & 16.74 & -0.61 & 0.61 & 0.51 \\
\hline 14 & 76.81 & 76.95 & -0.04 & 76.81 & 1.76 & -0.20 & 16.18 & 16.44 & -0.24 & 0.34 & \\
\hline 15 & 76.31 & 76.55 & -0.24 & 76.31 & 1.79 & -0.09 & 15.91 & 16.04 & -0.13 & 0.28 & \\
\hline
\end{tabular}

to study the effect of color on porcelain by varying the porcelain thickness. B2 porcelain shade was commonly used for all the samples. 0.5, 1 and $1.5 \mathrm{~mm}$ porcelain thickness were used to determine whether thickness of porcelain affected color effectiveness.

All the 15 samples were individually analyzed in a spectrophotometer and the data transferred to the computer. Keeping shade guide as control all the fifteen samples were compared to it. The resultant $\Delta \mathrm{E}$ we obtained. The analysis of samples for value shows that value changes are clearly significant for thickness differences. Value consistently increased, become less gray with increasing thickness. This can be interrupted as:

- With increasing thickness, the restoration becomes less affected by the graying (lower value) effect of the opaque layer. 
- With increasing thickness, the effect of the porcelain's translucency becomes greater by increasing the value. In the second part of the study, the effect of number of firings was evaluated, the same set of samples were fired two times and 10 times and evaluated. For all samples tested, no significant difference in any dimension of color could be defected for samples fired two and 10 times.

\section{CONCLUSION}

The thickness of porcelain significantly affects the color of a given porcelain sample. Increased thickness gives better results. Therefore, maximum tooth reduction without violating pulpal integrity is encouraged. So, adequate amount of tooth reduction around 1.5 to $2 \mathrm{~mm}$ in necessary to match the desired color.

On repeated firings two and 10 firing did not affect the color stability. Slight changes in color noticed in some samples, it may be attributed to the increase in density caused by the decrease of air bubbles trapped inside the porcelain. Changes in porcelain color were not sufficiently significant to cause rejection of the samples.

\section{REFERENCES}

1. Kenneth J. Anusavice. 'Phillips' Science of Dental Materials'. 11th edition. Elsevier Health Sciences Publications.

2. Chiche GJ, Pinault A, et al. Esthetics of anterior fixed prosthodontics. Chicago: Quintessence, 1994. p. 97-113.

3. Rosenstiel SF, Johnston WM, et al. The effect of manipulative variables on the color of ceramic metal restorations. J Prosthet Dent 1988;60(3):297-303.

4. Brewer JD, Alers CK, Garlapo DA, Sorensen SE, et al. Spectrometric analysis of the influence of metal substrates on the color of metal-ceramic restorations. J Prosthet Dent 1985;64(1):74-77.

5. Brewer JD, Glennon JS, Garlapo DA, et al. Spectrophotometric analysis of a non greening, metal fusing porcelain. J Prosthet Dent 1991;65(5):634-641.

6. O'brien WJ, Johnston WJ, Fanian F, et al. Double-layer color effects in porcelain systems. J Dent Res 1985;64(7):940-943.

7. Jorgenson MW, Goodkind RJ, et al. Spectrophotometric study of five porcelain shades relative to the dimensions of color, porcelain thickness, and repeated firings. J Prosthet Dent 1979;42(1):96-105.

8. Lund PS, Aquilino SA, Dixon DL, et al. Evaluation of the color and appearance of surface texture of opaque porcelain. Int J Prosthodont 1991;4(6):548-554.

9. Crispin BJ, Hewlett E, Seghi R, et al. Relative color stability of ceramic stains subjected to glazing temperatures. J Prosthet Dent 1991;66(1):20-23.

10. Culpepper WD. A comparative study of shade-matching procedures. J Prosthet Dent 1970;24(2):166-173.

11. Davidson HR, Friede E, et al. The size of acceptable color differences. J Opt Soc Am 1953;43(4):581-589.

12. CIE 1971. International commission on illumination. Colorimetry: official recommendations of the international commission on illumination, publication Cielab No. 15 (E-1.3.1), Bureau Central de La CIELAB Paris.

13. Banghi N. Color and glaze-effects of repeated firings. J Prosthet Dent 1982 April.

14. Jacobs SH, Goodacre CJ, Moore BK, Dykema RW, et al. Effect of porcelain thickness and type of metal ceramic alloy on color. J Prosthet Dent 1987;57(2):138-142.

15. Sawafuji F, Tusuchitoi H, Sato RR, et al. Using a computer color matching system in color reproduction of porcelain restoration part II: color reproduction of stratiform layered porcelain samples. Int J Prosthodont 1993;6(6):522-527.

16. Lund TW, Schwabacher WB, Chem B, Goodkind RJ, et al. Spectrophotometric study of the relationship between body porcelain color and applied metallic oxide pigments. J Prosthet Dent 1985;53(6):790-796. 